\title{
APRENDER PARA EMPREENDER? UMA ANÁLISE DO POTENCIAL E DA INTENÇÃO EMPREENDEDORA DE ESTUDANTES DE UMA ESCOLA DE EDUCAÇÃO PROFISSIONAL NO CEARÁ
}

\author{
Clayton Robson Moreira da Silva ${ }^{1}$ \\ Laís Vieira Castro Oliveira ${ }^{2}$ \\ Eva Maria Silva Costa ${ }^{3}$ \\ Francisco Adriano Gomes Bezerra ${ }^{4}$ \\ Raimundo Eduardo Silveira Fontenele ${ }^{5}$
}

\section{RESUMO}

Esta pesquisa analisou o potencial empreendedor e a intenção empreendedora de estudantes de uma escola de educação profissional no Ceará, por meio de uma pesquisa do tipo survey, com 477 estudantes. Os resultados indicam que os alunos do curso de comércio apresentaram intenção empreendedora superior em relação aos demais cursos, e que a intenção empreendedora é explicada por algumas características do potencial empreendedor. Assim, a pesquisa contribui para o campo da educação profissional à medida em que verificou fatores associados à intenção empreendedora de estudantes, preenchendo uma lacuna na literatura no que concerne ao perfil empreendedor de estudantes dessa modalidade de ensino, dando destaque a uma política de educação orientada ao empreendedorismo e à formação profissional para o trabalho.

Palavras-chave: empreendedorismo; perfil empreendedor; potencial empreendedor; intenção empreendedora; educação profissional.

\section{LEARNING FOR ENTREPRENEURSHIP? AN ANALYSIS OF THE ENTREPRENEURIAL POTENTIAL AND INTENTION OF STUDENTS AT A PROFESSIONAL EDUCATION SCHOOL IN CEARÁ}

\begin{abstract}
This research analyzed the entrepreneurial potential and the entrepreneurial intention of students at a professional education school in Ceará, through a survey, with 477 students. The

\footnotetext{
${ }^{1}$ Instituto Federal de Educação, Ciência e Tecnologia do Piauí, <clayton.silva@ifpi.edu.br>

${ }^{2}$ Instituto Federal de Educação, Ciência e Tecnologia do Piauí, <lais.castro@ifpi.edu.br>

${ }^{3}$ Secretária da Educação do Estado do Ceará, <evamaria_costa@hotmail.com>

${ }^{4}$ Universidade Estadual do Ceará, <adryan.bezerra@gmail.com>

${ }^{5}$ Universidade Federal do Ceará, <eduardo@ufc.br>
} results indicate that students of the commerce course presented higher entrepreneurial intention in relation to the other courses, and that the entrepreneurial intention is explained by some 
entrepreneurial potential characteristics. Thus, the research contributes to the area of professional education once it has verified factors associated with entrepreneurial intention among students, filling a gap in the literature regarding the entrepreneurial profile of students of this type of education, highlighting a policy of entrepreneurial education and vocational training for work.

Keywords: entrepreneurship; entrepreneurial profile; entrepreneurial potential; entrepreneurial intention; professional education.

\section{INTRODUÇÃO}

Nos últimos anos, no Brasil, os estudos sobre empreendedorismo vêm ganhando destaque. A preocupação com a criação de pequenas empresas duradouras e a necessidade da redução das altas taxas de mortalidade desses empreendimentos são alguns fatores para o destaque do tema no âmbito acadêmico (ALMEIDA et. al., 2008). Nessa perspectiva, compreende-se que, no atual cenário empresarial, as organizações demandam trabalhadores criativos e inovadores, que possam contribuir e desenvolver diferenciais competitivos no mercado (GÜROL; ATSON, 2006).

Para isto, é fundamental o estímulo da prática por meio da educação e capacitação empreendedora nos diversos ambientes de ensino (HONG et al., 2012; PADILLAMELÉNDEZ; FERNÁNDEZ-GÁMEZ; MOLINA-GÓMEZ, 2014). Dessa forma, as instituições educacionais precisam estabelecer incentivos nesta direção, desempenhando o papel de incubadora e estimuladora de verdadeiros empreendedores (ALMEIDA et al., 2008). No âmbito acadêmico, embora as pesquisas abordem esta temática sob diferentes perspectivas, os estudos envolvendo estudantes apresentam um interesse constante dos pesquisadores (IZUKA; MORAES, 2014).

Nesse contexto, as pesquisas sobre o empreendedorismo entre estudantes parece ter maior destaque no que se refere ao perfil empreendedor de estudantes de ensino superior, uma vez que observa-se um grande contingente de pesquisas voltadas ao público universitário (GÜROL; ATSAN, 2006; NABI; WALMSLEY, 2010; YILDIRIM; ASKUN, 2012; KOE et al., 2012; HONG et al., 2012; ARAÚJO et al., 2012; ECKERT et al., 2013; PADILLA-MELÉNDEZ; FERNÁNDEZ-GÁMEZ; MOLINA-GÓMEZ, 2014; ROCHA; FREITAS, 2014; IIZUKA; MORAES, 2014; SEIDAHMETOV et al., 2014; PANC, 2015; VARAMÄKI et al., 2015; LIMA et al., 2015; CHING; KITAHARA, 2015; LIMA et al., 2016).

Por outro lado, pesquisas envolvendo estudantes de nível médio e na educação profissional (PAÇO et al., 2011; DINIS et al., 2013; MALACARNE; BRUSTEIN; BRITO, 
2014; ROSIQUE-BLASCO; MADRID-GUIJARRO; GARCÍA-PÉREZ-DE-LEMA，2016; BIRCHLER; TEIXEIRA, 2017; SIQUEIRA; COSTA; SACRAMENTO, 2017; SILVEIRA; SANCHES, 2017; SILVA; OLIVEIRA; PINHO, 2017) parecem ser ainda incipientes. No entanto, estudos dessa natureza têm emergido com o intuito de investigar as questões sobre o perfil empreendedor de estudantes a partir de uma outra perspectiva. Dessa forma, embora as pesquisas com estudantes da educação profissional ainda sejam poucas quando comparadas ao mainstream das pesquisas com universitários, observa-se um avanço nos estudos com discentes desta modalidade de ensino.

Em 2008, o Governo do Estado do Ceará delineou como política pública de educação a criação de Escolas Estaduais de Educação Profissional (EEEP) como uma estratégia de integrar o ensino médio à formação profissional de nível técnico, ofertando educação em tempo integral a jovens do estado (CEARÁ, 2008). Este modelo de educação integrada possibilita que os estudantes desenvolvam habilidades fundamentais para o ingresso no mercado de trabalho, promovendo o diálogo entre educação formal e o mundo do trabalho (SEDUC-CE, 2018).

Esta política de educação cearense tem priorizado o ensino do empreendedorismo em todos os cursos técnicos ofertados pelas EEEPs, uma vez que o tema é abordado com a finalidade de proporcionar a capacitação dos educandos com foco na concepção e aperfeiçoamento de habilidades empreendedoras, que colaborem para o planejamento e desenvolvimento de negócios sustentáveis e focados na identificação de oportunidades no mercado (SEDUC-CE, 2018).

Considerando o que foi exposto e tendo em vista os esforços do poder público cearense em desenvolver políticas públicas de educação profissional, com foco na formação técnica e empreendedora de estudantes, este estudo parte da seguinte questão norteadora: qual a relação entre o potencial empreendedor (PE) e a intenção empreendedora (IE) dos estudantes da educação profissional? Como objetivo geral, a pesquisa busca analisar o PE e a IE de estudantes de uma escola da educação profissional no Ceará. De forma específica, este estudo buscou: (i) identificar o PE e a IE dos estudantes; (ii) associar características do perfil dos estudantes com a IE; e (iii) verificar a influência do PE sobre a IE dos estudantes.

Para responder à questão de pesquisa e alcançar os objetivos propostos, realizou-se uma pesquisa do tipo survey, com abordagem quantitativa, em uma EEEP, localizada no Estado do Ceará. A escola oferta cursos técnicos de forma integrada ao ensino médio, a saber: (i) técnico em administração; (ii) técnico em comércio; (iii) técnico em enfermagem; e (iv) técnico em 
informática. No ano letivo de 2017, a escola contava com um total de 513 alunos regularmente matriculados, dos quais 477 participaram desta pesquisa.

De acordo com Ferreira, Alcântara e Freitas (2013) para o desenvolvimento econômico de um país, os empreendedores são fundamentais, pois alavancam a economia por meio da inovação. No cenário nacional, o ensino do empreendedorismo surge a partir da necessidade das instituições de ensino incentivar e desenvolver o empreendedorismo entre os jovens. Neste contexto, ganha relevância a existência de pesquisas que buscam compreender e identificar o potencial e o perfil empreendedor de estudantes.

\section{REVISÃO DA LITERATURA}

\section{Empreendedorismo}

O empreendedorismo é uma temática que vem ganhando relevância nas pesquisas científicas. Segundo Rocha e Freitas (2014) e Lima et. al. (2015), esse avanço neste campo de pesquisa pode estar relacionado ao desempenho da economia e ao desenvolvimento local e nacional. A ação de empreender possibilita a criação de empregos e estimula a geração de renda, tornando-se uma alternativa interessante para os governos e sociedades (ROCHA; FREITAS, 2014).

Diante do cenário de mudanças ocasionado pelas transformações tecnológicas, sociais e econômicas, o empreendedorismo está cada vez mais presente no cotidiano dos brasileiros. Entretanto, sua origem está ligada a um passado europeu. O termo Entrepreneur é de origem francesa e está relacionado com aquele que assume riscos e começa algo novo, e o primeiro uso do termo pode ser creditado à Marco Polo, quando em suas rotas comerciais para o Oriente assumiu uma posição de risco ao desbravar o novo mundo, levando mercadorias de alguns capitalistas (ARAÚJO et. al., 2012; SILVA, OLIVEIRA, PINHO, 2017).

Em uma breve análise histórica do termo empreendedorismo, na Idade Média, o termo empreendedor foi utilizado para definir aquele que gerenciava grandes projetos de produção. Esse indivíduo não assumia grandes riscos, e apenas gerenciava os projetos, utilizando os recursos disponíveis. No século XVII, ocorreram os primeiros indícios de relação entre assumir riscos e empreendedorismo, o empreendedor estabelecia um acordo contratual com o governo para realizar algum serviço ou fornecer algum produto. Já no século XVIII, o capitalista e o empreendedor são diferenciados, provavelmente devido ao início da industrialização que ocorria no mundo. Nos séculos XIX e XX, empreendedores eram frequentemente confundidos 
com os gerentes ou administradores (DORNELAS, 2008).

No Brasil, o empreendedorismo ganhou propulsão a partir da criação de empresas como o SEBRAE e a SOFITEX, a partir da década de 1990. Na sequência emergiram o Programa Brasil Empreendedor do Governo Federal e a criação de diversos cursos e programas em universidades. Houve também um elevado crescimento de startups e a proliferação de franquias, tudo isso devido ao momento propício do país (SILVA, OLIVEIRA, PINHO, 2017).

No que concerne às definições do termo empreendedorismo, é possível encontrar diversas definições na literatura, destacando-se o conceito econômico de empreendedorismo, popularizado pelo economista Joseph Schumpeter, em 1945. Em qualquer definição de empreendedorismo encontram-se, pelo menos, os seguintes aspectos referentes ao empreendedor: iniciativa para criar/inovar e paixão pelo o que faz; utilização dos recursos disponíveis de forma criativa transformando o ambiente social e econômico onde vive; aceita assumir os riscos e a possibilidade de fracassar (DORNELAS, 2008; SILVA, OLIVEIRA, PINHO, 2017).

No contexto atual, o empreendedorismo está cada vez mais consolidando-se entre os jovens (KOE et al., 2012), impulsionando sobremaneira a abertura de novos negócios e alavancando a criatividade de jovens empreendedores (SEIDAHMETOV et al., 2014). Dessa forma, crescem o número de instituições educacionais, unidades governamentais, sociedade e corporações que buscam disseminar esse fenômeno (ROSIQUE-BLASCO; MADRIDGUIJARRO; GARCÍA-PÉREZ-DE-LEMA, 2016). Ainda, de acordo com Araújo et. al. (2012) e Hisrich e Peters (2004), a educação empreendedora tem alcançado grande relevância em termos de cursos e pesquisa e isso reflete-se no elevado número de universidades e faculdades que oferecem pelo menos um curso de empreendedorismo.

No âmbito empresarial, segundo Seidahmetov et al. (2014), o desenvolvimento dos pequenos negócios atua como um dos importantes mecanismos de diversificação da economia. No entanto, não menos importante é a criação de condições favoráveis para o aumento da atividade comercial de grandes segmentos da população, especialmente para os jovens. Diante desse cenário, faz-se importante o conhecimento de características relacionadas ao perfil empreendedor de jovens estudantes, tais como o PE e a IE destes estudantes.

\section{Perfil Empreendedor}

Diversos estudos buscaram identificar comportamentos, características e competências 
comuns encontradas em indivíduos que atuam no campo do empreendedorismo (ROCHA; FREITAS, 2014), uma vez que o perfil empreendedor pode estar, entre outras coisas, relacionado às perspectivas futuras dos indivíduos. No campo da educação, o estímulo ao empreendedorismo pode despertar a criatividade do estudante, assim como pode conduzi-lo ao processo de delineamento de novas alternativas de vida. Além disso, esse processo possibilita o desenvolvimento de uma consciência inovadora. Assim, identificar os componentes específicos das características comportamentais empreendedoras subsidia a discussão sobre o empreendedorismo de jovens estudantes (CHING; KITAHARA, 2015).

Nos estudos que abordam a temática do empreendedorismo, é possível identificar fatores ou características que influenciam o comportamento empreendedor por meio de fatores individuais, sociais e ambientais. O primeiro enfatiza as características de personalidade dos empreendedores; os fatores sociais versam sobre o passado pessoal e familiar e experiências de vida; e os fatores ambientais explanam as oportunidades na carreira, o impacto das condições de mercado e a perturbação social (GUROL; ATSAN, 2006).

Para Padilla-Meléndez, Fernández-Gámez e Molina-Gómez (2014), as pesquisas nessa área apresentam duas perspectivas, uma relacionada ao contexto e a outra concerne às características pessoais. A primeira está relacionada com a educação empreendedora, as diferenças regionais, a cultura, capital social, etc. Já as características pessoais têm como direcionamento desenvolver um instrumento para medir a orientação empreendedora relacionada às características psicológicas.

Nesse contexto, McClelland (1972) foi um dos pioneiros a usar as teorias da ciência comportamental para desenvolver pesquisas empíricas sobre a motivação para empreender. $\mathrm{O}$ autor argumenta a existência de dez características comportamentais empreendedoras: (i) busca de oportunidades e iniciativa; (ii) capacidade de assumir riscos calculados; (iii) persistência; (iv) exigência de qualidade e eficiência; (v) comprometimento; (vi) busca de informações; (vii) determinação de metas; (viii) planejamento e monitoramento sistemático; (ix) capacidade de persuasão e rede de contatos; e (x) independência e autoconfiança. Essas características foram categorizadas em três grandes grupos: (i) necessidade de realização; (ii) planejamento; e (iii) poder (CHING, KITAHARA, 2015; SILVA, OLIVEIRA, PINHO, 2017).

No que concerne ao potencial empreendedor de estudantes, para o treinamento de empresários ou para a seleção de candidatos ao ingresso em incubadoras de empresas, Santos (2008) argumenta que não foi encontrada ainda uma escala validada, produzida no Brasil e de 
fácil aplicação. Dessa forma, a fim de suprir essa lacuna, o autor propôs cenários, fatores, constructos e itens que permitiram a elaboração de uma escala. Inicialmente, a escala contava com 128 itens. Após os testes estatísticos, permaneceram 49 itens referentes a características do perfil empreendedor, divididos em dez dimensões: (i) oportunidade; (ii) persistência; (iii) eficiência; (iv) informações; (v) planejamento; (vi) metas; (vii) controle; (viii) persuasão; (ix) rede de relações; e (x) intenção de empreender. Assim, esta escala foi elaborada e testada no contexto brasileiro, e serve para avaliar a IE e PE, motivo que levou à sua utilização nesta pesquisa.

\section{Estudos sobre Perfil Empreendedor de Estudantes de Nível Médio}

Os estudos que abordam a temática empreendedorismo numa perspectiva educacional vem ganhando destaque no âmbito nacional e internacional (SILVA; OLIVEIRA; PINHO, 2017). Diversos autores discutem sobre perfil, IE e PE de estudantes em diversas áreas. Porém, poucos são os estudos que discutem essa temática no contexto do ensino médio, sendo a temática abordada de forma mais recorrente em cenários universitários.

Apesar da lacuna de estudos envolvendo estudantes do ensino médio, foram observados alguns estudos no cenário internacional. A pesquisa de Paço et al. (2011) buscou identificar fatores que voltados à intenção de criar novos negócios entre alunos do ensino médio de Portugal. Os autores aplicaram questionários com estudantes de 14 e 15 anos. Os achados desse estudo revelam que as atitudes pessoais e o controle comportamental dos indivíduos influenciam positivamente a IE. Além disso, os autores sugerem que programas de educação empreendedora podem contribuir para desenvolvimento de competências relacionadas ao empreendedorismo, impactando diretamente na IE dos estudantes.

Rosique-Blasco, Madrid-Guijarro e García-Pérez-de-Lema (2016) desenvolveram uma pesquisa na Região de Múrcia, Espanha, com o objetivo de explorar como habilidades empreendedoras e fatores socioculturais afetam a propensão dos alunos do ensino médio para as opções empresariais em suas futuras carreiras. Os autores aplicaram questionários e utilizaram modelo Logit para as estimações estatísticas. Os resultados da pesquisa apontam que tanto as habilidades quanto os fatores socioculturais afetam positivamente a IE dos estudantes do ensino médio.

No contexto brasileiro, Malacarne, Brustein e Brito (2014) desenvolveram uma pesquisa com o objetivo de compreender a experiência de formação de jovens empreendedores do 
Instituto Federal do Espírito Santo (IFES), marcada pela realização de ações e iniciativas lúdicas de preparação dos alunos para participar de olimpíadas nacionais e internacionais de agropecuária. Os resultados indicam que, após as ações desenvolvidas, observou-se uma nova postura dos alunos, que apresentaram maior dedicação e envolvimento nas disciplinas técnicas, além de ampliarem suas percepções em relação à capacitação técnica e formação adequada para tomar decisões considerando aspectos ambientais, sociais e econômicos.

Silveira e Sanches (2017) analisaram a existência de diferenças nas características empreendedoras entre os alunos que estudaram e os que não estudaram a disciplina de empreendedorismo. Para tanto, os autores elaboraram um questionário que foi validado e testado e realizaram testes de hipótese. Os resultados sinalizaram que a disciplina de empreendedorismo influencia no desenvolvimento de características empreendedoras, tais como: autoconfiança; autoconsciência; autoeficaz; capacidade de aprendizagem; conhecimento do mercado; conhecimento do produto; detecta oportunidades; habilidade para conduzir situações; habilidade na utilização de recursos; necessidade de realização.

Silva, Oliveira e Pinho (2017) analisaram a percepção de professores e estudantes de nível médio sobre o perfil empreendedor dos estudantes de uma EEEP, no Estado do Ceará. Para tanto os autores recorreram a uma pesquisa qualitativa, onde foram realizadas entrevistas com alguns professores e estudantes da escola. Verificou-se que há alinhamento entre a percepção dos entrevistados no que diz respeito ao perfil empreendedor dos estudantes, considerando o que é proposto pela literatura no que tange ao perfil empreendedor.

\section{METODOLOGIA}

\section{Amostra e Coleta de Dados}

O estudo teve como população os alunos de uma EEEP, localizada no Estado do Ceará. A EEEP analisada contava, no ano letivo de 2017, com um total de 513 alunos matriculados em quatro diferentes cursos técnicos ofertados na modalidade integrada ao ensino médio, a saber: (i) técnico em administração; (ii) técnico em comércio; (iii) técnico em enfermagem e; (iv) técnico em informática. Conduziu-se uma pesquisa do tipo survey, em que foram aplicados questionários in loco, no mês de setembro de 2017, com os alunos dos quatro cursos ofertados pela escola. Dos 513 alunos matriculados no ano de 2017, foram obtidos 477 questionários válidos, que compuseram a amostra desta pesquisa. 
SSN: $2594-4827$

\section{Questionário}

$\mathrm{O}$ instrumento de coleta desenvolvido para esta pesquisa foi um questionário composto por duas partes. A primeira compreende seis perguntas destinadas à caracterização dos respondentes. A segunda parte do questionário serviu para medir o PE e IE dos estudantes e trata-se de uma escala desenvolvida e validada por Santos (2008) no contexto brasileiro - a escala é do tipo Likert de 5 pontos, em que 1 indica que o respondente discorda totalmente da assertiva e 5 que o respondente concorda totalmente.

\section{Procedimentos Estatísticos}

Inicialmente, utilizou-se análise descritiva a fim de caracterizar a amostra. Em seguida, verificou-se a confiabilidade das dimensões da escala de PE e IE por meio do cálculo do alfa de Cronbach, que, segundo Hair Jr. et al. (2009), deve apresentar coeficiente superior 0,6 para que seja considerado adequado para as análises seguintes. Após verificada a confiabilidade das dimensões da escala, recorreu-se à Análise Fatorial Exploratória (AFE).

$\mathrm{Na} \mathrm{AFE}$, foram observados os valores da medida de Kaiser-Meyer-Olkin (KMO), do teste de esfericidade de Bartlett e a variância explicada pelo fator. De acordo com Hutcheson e Sofroniou (1999), os valores do KMO inferiores a 0,5 são inaceitáveis; entre 0,5 e 0,7 são aceitáveis, porém baixos; entre 0,7 e 0,8 são bons; entre 0,8 e 0,9 são ótimos; e acima de 0,9 são excelentes. Ainda, foram verificadas as comunalidades e as cargas fatoriais, que devem ser superiores a 0,5 (HAIR JR. et al., 2009).

Definidos os parâmetros acima, realizou-se uma primeira AFE, em que foram verificadas as comunalidades e cargas fatoriais dos itens da escala. Foram excluídos os itens que apresentaram comunalidades inferiores a 0,5. Após esses procedimentos, observou-se que dos 49 itens da escala de PE e IE, restaram 40, que apresentaram comunalidades e cargas fatoriais com valores adequados, como sugerem Hair Jr. et al. (2009). Posteriormente, realizou-se nova AFE com os 40 itens que é apresentada na seção de resultados.

O Quadro 1 apresenta as assertivas referentes aos 40 itens restantes da escala proposta por Santos (2008) divididos em dimensões. Ressalta-se que, originalmente, a escala de PE e IE de Santos (2008) é dividida em dez dimensões: uma relacionada à IE; e nove relacionadas ao PE (oportunidade, persistência, eficiência, informações, planejamento, metas, controle, persuasão e rede de relações). Após os procedimentos de pré-análise, que culminaram na 
exclusão de nove itens da escala, verificou-se que todos os itens da dimensão "informações" do PE empreendedor, foram excluídos, fazendo com que essa dimensão não figurasse nas análises.

Quadro 1 - Itens da escala de Intenção Empreendedora e Potencial Empreendedor.

\begin{tabular}{|c|c|c|}
\hline Construto & $\begin{array}{l}\mathrm{N}^{\mathbf{0}} \text { de } \\
\text { Itens }\end{array}$ & Itens \\
\hline $\begin{array}{c}\text { Intenção } \\
\text { Empreendedora } \\
\text { (IE) }\end{array}$ & 4 & $\begin{array}{l}\text { IE1: Com certeza um dia terei meu próprio negócio. } \\
\text { IE2: Mesmo que eu trabalhe para outrem não abandonarei o desejo de } \\
\text { ter meu próprio negócio. } \\
\text { IE3: Minha maior realização será ter o meu próprio negócio. } \\
\text { IE4: Ser autoempregado, um empreendedor, sempre foi minha } \\
\text { aspiração. }\end{array}$ \\
\hline $\begin{array}{l}\text { Oportunidade } \\
\qquad(\mathrm{OP})\end{array}$ & 3 & $\begin{array}{l}\text { OP1: Percebo as necessidades dos outros e como elas podem ser } \\
\text { satisfeitas. } \\
\text { OP2: Gosto de me informar sobre as necessidades das pessoas. } \\
\text { OP5: Creio sinceramente que as oportunidades estão aí para serem } \\
\text { identificadas. }\end{array}$ \\
\hline $\begin{array}{l}\text { Persistência } \\
\qquad \text { (PES) }\end{array}$ & 6 & $\begin{array}{l}\text { PES1: Entendo que os obstáculos existem para serem superados. } \\
\text { PES2: Quando levo um tombo levanto e continuo. } \\
\text { PES3: Quando cometo um erro de planejamento, redefino as coisas e } \\
\text { vou em frente. } \\
\text { PES4: Encaro o fracasso como fonte de aprendizado para não cometer } \\
\text { o mesmo erro novamente. } \\
\text { PES5: Não me deixo abater pelo fracasso. } \\
\text { PES6: Busco, de forma permanente, atingir meus objetivos. }\end{array}$ \\
\hline $\begin{array}{l}\text { Eficiência } \\
\qquad(\text { EFI) }\end{array}$ & 3 & $\begin{array}{l}\text { EFI1: Gosto de cumprir prazos. } \\
\text { EFI2: Gosto de realizar meus trabalhos de forma correta e dentro dos } \\
\text { prazos estabelecidos. } \\
\text { EFI3: Quando é preciso, faço as adaptações necessárias para que as } \\
\text { coisas funcionem. }\end{array}$ \\
\hline $\begin{array}{l}\text { Planejamento } \\
\quad \text { (PLA) }\end{array}$ & 3 & $\begin{array}{l}\text { PLA1: Não consigo fazer nada sem um planejamento bem detalhado. } \\
\text { PLA2: Quem não consegue planejar suas atividades tende a fracassar. }\end{array}$ \\
\hline
\end{tabular}




\begin{tabular}{|c|c|c|}
\hline & & $\begin{array}{l}\text { PLA3: Só sei se estou acertando se tiver um planejamento das minhas } \\
\text { atividades. }\end{array}$ \\
\hline $\begin{array}{l}\text { Metas } \\
(\text { MET) }\end{array}$ & 6 & $\begin{array}{l}\text { MET1: O que pretendo alcançar está claramente definido. } \\
\text { MET2: Sei determinar claramente quais são meus objetivos e metas. } \\
\text { MET3: Sei que posso definir meus rumos de curto, médio e longo } \\
\text { prazo. } \\
\text { MET4: Sei onde pretendo chegar e o quanto pretendo alcançar. } \\
\text { MET5: Tenho convicção que vou alcançar meus objetivos e metas. } \\
\text { MET6: Sou capaz de traçar um rumo e estabelecer os ganhos que vou } \\
\text { ter no final. }\end{array}$ \\
\hline $\begin{array}{l}\text { Controle } \\
(\mathrm{CON})\end{array}$ & 5 & $\begin{array}{l}\text { CON1: Meus controles me auxiliam na revisão de meus planos. } \\
\text { CON2: Costumo fazer anotações e manter registros das minhas ações. } \\
\text { CON3: Consulto meus registros antes de tomar decisões. } \\
\text { CON4: Vejo o planejamento como um guia para controlar as minhas } \\
\text { ações. } \\
\text { CON5: Costumo verificar se as coisas estão acontecendo como } \\
\text { planejei. }\end{array}$ \\
\hline $\begin{array}{l}\text { Persuasão } \\
\text { (PER) }\end{array}$ & 6 & $\begin{array}{l}\text { PER1: Posso convencer pessoas a superar conflitos e atuar em equipe } \\
\text { objetivando alcançar determinado resultado. } \\
\text { PER2: Sou capaz de estimular as pessoas a realizarem tarefas para as } \\
\text { quais estão desmotivadas. } \\
\text { PER3: Sei quais as palavras e ações adequadas para estimular as } \\
\text { pessoas. } \\
\text { PER4: Tenho formas de convencer as pessoas a mudarem de opinião. } \\
\text { PER5: Ajo de forma a motivar as pessoas e manter alto o moral em } \\
\text { qualquer situação. } \\
\text { PER6: Sei que sou capaz de liderar uma equipe e atingir metas. }\end{array}$ \\
\hline $\begin{array}{c}\text { Rede de } \\
\text { Relações } \\
\text { (RR) }\end{array}$ & 4 & $\begin{array}{l}\text { RR1: Procuro estabelecer uma boa rede de relacionamentos com } \\
\text { conhecidos, amigos e pessoas que possam me ser úteis. } \\
\text { RR2: Procuro manter contato constante com as pessoas de minha rede } \\
\text { de relações. }\end{array}$ \\
\hline
\end{tabular}




\begin{tabular}{|l|l|}
\hline & $\begin{array}{l}\text { RR3: Tenho como manter contato fácil com as pessoas de minha rede } \\
\text { de relações. } \\
\text { RR4: Sempre que posso procuro atender as solicitações que me fazem } \\
\text { as pessoas de minha rede de relações. }\end{array}$ \\
\hline
\end{tabular}

Nota: A versão final da escala contou com um total de 40 itens, divididos em 9 dimensões (uma dimensão relacionada à IE e oito dimensões relacionadas ao PE.

Fonte: Dados da pesquisa (2017).

Após realizada a AFE, conduziu-se o teste estatístico de Análise de Correspondência (ANACOR), a fim de verificar a associação entre o perfil dos respondentes e a IE. A ANACOR é uma técnica estatística que tem como finalidade verificar a associação entre varáveis categóricas por meio de um mapa perceptual. Este método possibilita uma análise visual sobre o nível de associação entre variáveis, considerando suas posições no mapa (FÁVERO et al., 2009). Ressalta-se que este método utiliza variáveis não-métricas, por conta disso foi necessário fazer a categorização de algumas variáveis. O Quadro 2 apresenta as variáveis utilizadas na ANACOR, bem como sua operacionalização e categorização.

Quadro 2 - Variáveis utilizadas na ANACOR.

\begin{tabular}{|c|c|c|}
\hline Variável & Operacionalização & Categorização \\
\hline $\begin{array}{l}\text { Intenção } \\
\text { Empreendedora } \\
\text { (IE) }\end{array}$ & $\begin{array}{l}\text { Variável latente relacionada ao construto IE, } \\
\text { calculada pela média dos itens correspondentes a } \\
\text { essa dimensão da escala. Os valores das médias } \\
\text { dos respondentes foram divididos em quartis. }\end{array}$ & $\begin{array}{l}\text { 1- Baixo } \\
2 \text { - Médio Baixo } \\
3 \text { - Médio Alto } \\
4 \text { - Alto }\end{array}$ \\
\hline Sexo & $\begin{array}{l}\text { Variável categórica relacionada ao sexo do } \\
\text { indivíduo. }\end{array}$ & $\begin{array}{l}1-\text { Masculino } \\
2-\text { Feminino }\end{array}$ \\
\hline Idade & $\begin{array}{l}\text { Variável categórica referente à idade dos } \\
\text { respondentes. }\end{array}$ & $\begin{array}{l}1-14 \text { ou } 15 \text { anos } \\
2-16 \text { ou } 17 \text { anos } \\
3-18 \text { ou } 19 \text { anos }\end{array}$ \\
\hline Curso & $\begin{array}{l}\text { Variável categórica referente ao curso do } \\
\text { estudante. }\end{array}$ & $\begin{array}{l}\text { 1- Administração } \\
2 \text { - Comércio } \\
3 \text { - Enfermagem } \\
4 \text { - Informática }\end{array}$ \\
\hline
\end{tabular}


SSN: $2594-4827$

\begin{tabular}{|l|l|l|}
\hline Série & $\begin{array}{l}\text { Variável categórica referente à série que o } \\
\text { indivíduo cursa. }\end{array}$ & $\begin{array}{l}1-1^{\circ} \text { Ano do Ensino Médio } \\
2-2^{\circ} \text { Ano do Ensino Médio } \\
3-3^{\circ} \text { Ano do Ensino Médio }\end{array}$ \\
\hline
\end{tabular}

Fonte: Elaborado pelos autores (2017).

Conduziu-se o teste qui-quadrado a fim de verificar a dependência entre as variáveis, que é requisito indispensável para a realização da ANACOR (FÁVERO et al., 2009). Foram consideradas adequadas as associações que apresentaram significância estatística inferior a 5\%.

Por fim, realizou-se uma Regressão Linear Múltipla a fim de verificar a influência das variáveis relacionadas ao PE sobre a IE dos estudantes. Para tanto, utilizou-se como variável dependente a variável latente relacionada à IE e, como variáveis explicativas, as variáveis latentes referentes ao PE (OP, PES, EFI, PLA, MET, CON, PER e RR), que foram obtidas por meio da AFE e calculadas pela média dos itens que com põem cada dimensão. Dessa forma, a Equação 1 apresenta o modelo utilizado:

$I E=\beta_{0}+\beta_{1} O P+\beta_{2} P E S+\beta_{3} E F I+\beta_{4} P L A+\beta_{5} M E T+\beta_{6} C O N+\beta_{7} P E R+\beta_{8} R R+\varepsilon$

Para a execução dos testes estatísticos, utilizou-se o software Statistical Package for Social Sciences (SPSS), versão 22.0.

\section{APRESENTAÇÃO DOS RESULTADOS}

\section{Perfil dos Respondentes}

Em relação à amostra, observou-se que a maioria dos estudantes é do sexo feminino $(54,72 \%)$ e se concentra na faixa entre 16 ou 17 anos (64,15\%), seguido do grupo que corresponde aos indivíduos de 14 ou 15 anos $(27,67 \%)$ e do grupo dos respondentes que estão com 18 ou 19 anos $(8,18 \%)$, respectivamente. Além disso, observou-se que 26,83\% são alunos do curso técnico em informática, $25,58 \%$ são alunos do curso técnico em comércio, $24,11 \%$ são alunos do curso técnico em administração e 23,48\% são alunos do curso técnico em enfermagem. No que concerne à divisão por série, 35,64\% estão no $1^{\circ}$ Ano do Ensino Médio, $32,28 \%$ pertencem ao $2^{\circ}$ Ano do Ensino Médio e 32,08\% estão no $3^{\circ}$ Ano do Ensino Médio. 


\section{Confiabilidade dos Dados}

Antes dar início à análise multivariada, por meio da AFE, ANACOR e regressão linear múltipla, calculou-se o Alfa de Cronbach com o intuito de verificar a confiabilidade dos dados. Assim, verificou-se a confiabilidade dos itens agrupados em 9 dimensões: uma delas relacionada à IE e 8 relacionadas ao $\mathrm{PE}$, conforme demonstra a Tabela 1.

Tabela 1 - Confiabilidade das Dimensões da Escala.

\begin{tabular}{lllr}
\hline Construto & Dimensões & Descrição & a de Cronbach \\
\hline Intenção Empreendedora & Dimensão 1 & Intenção Empreendedora (IE) & 0,936 \\
\hline & Dimensão 2 & Oportunidade (OP) & 0,839 \\
& Dimensão 3 & Persistência (PES) & 0,609 \\
& Dimensão 4 & Eficiência (EFI) & 0,825 \\
& Dimensão 5 & Planejamento (PLA) & 0,749 \\
Potencial Empreendedor & Dimensão 6 & Metas (MET) & 0,732 \\
& Dimensão 7 & Controle (CON) & 0,853 \\
& Dimensão 8 & Persuasão (PER) & 0,827 \\
& Dimensão 9 & Rede de Relações (RR) & 0,852
\end{tabular}

Fonte: Dados da pesquisa (2017).

Os resultados evidenciados na Tabela 1 revelam que todas as dimensões da escala apresentaram confiabilidade suficiente para a condução dos demais testes estatísticos, uma vez que apresentaram Alfa de Cronbach superior a 0,6, conforme sugerem Hair Jr. et al. (2009).

\section{Validação e Confirmação do Agrupamento de Itens por Dimensão (AFE)}

Conforme descrito na seção de metodologia, após verificada a confiabilidade da escala, realizou-se a AFE, onde foram verificadas as comunalidades e cargas fatoriais dos itens da escala. Foram excluídos os itens que apresentaram comunalidades inferiores a 0,5. Após esses procedimentos, observou-se que, dos 49 itens da escala de PE e IE de Santos (2008), restaram 40 itens com comunalidades e cargas fatoriais com valores adequados $(>0,5)$.

Realizou-se nova AFE com o intuito de confirmar o agrupamento dos itens dos construtos estudados. Realizaram-se testes KMO e de Bartlett, com rotação Varimax. Com base nos 40 itens da escala, observou-se KMO igual a 0,917 e teste de Bartlett apresentou significância 
inferior ao nível de $1 \%$, indicando nível de correlação entre os itens suficiente para a execução da AFE. Os resultados apresentaram 9 componentes que obedeceram ao critério Kaiser de eigenvalues superiores a 1 , os quais explicam $62,298 \%$ da variância para os construtos. A Tabela 2 apresenta os resultados da AFE.

Tabela 2 - Componentes extraídos da escala de Intenção Empreendedora e Potencial Empreendedor.

\begin{tabular}{|c|c|c|c|c|c|c|c|c|c|c|}
\hline \multirow{2}{*}{ Dimensão } & \multirow{2}{*}{$\begin{array}{l}\text { Código } \\
\text { do Item }\end{array}$} & \multicolumn{9}{|c|}{ Componentes } \\
\hline & & 1 & 2 & 3 & 4 & 5 & 6 & 7 & 8 & 9 \\
\hline \multirow{6}{*}{$\begin{array}{c}\text { Persistência } \\
\text { (PES) }\end{array}$} & PER3 & ,756 & ,215 & ,097 & ,097 & ,084 & ,052 & ,036 & ,117 & , 117 \\
\hline & PER4 & ,753 &, 143 & , 129 & 053 & ,089 & ,103 & ,099 &,- 024 & ,078 \\
\hline & PER2 & ,743 &, 111 & , 153 & ,094 &, 145 & ,073 & ,026 & , 136 & ,085 \\
\hline & PER5 & ,649 &, 155 & , 160 &, 174 &, 142 & ,110 &, 183 & ,062 & , 123 \\
\hline & PER1 & ,626 &, 140 & , 112 & ,222 & ,273 & ,055 & ,093 & ,014 & ,098 \\
\hline & PER6 & ,518 & , 169 & ,028 & ,189 & ,246 &, 215 & ,001 & , 190 & ,116 \\
\hline \multirow{6}{*}{$\begin{array}{l}\text { Metas } \\
\text { (MET) }\end{array}$} & MET2 &, 113 & ,790 & ,084 & ,137 & ,060 & ,163 &, 128 & ,071 & ,071 \\
\hline & MET4 &, 147 & ,748 & ,212 & ,129 & ,077 &, 030 & ,080 & ,074 & , 177 \\
\hline & MET1 &, 145 & ,715 & ,034 & ,080 & , 040 & ,110 & ,206 &, 127 &,- 016 \\
\hline & MET3 & ,224 & ,695 & ,066 & , 187 & ,097 & ,059 & ,021 & ,069 & , 159 \\
\hline & MET5 &, 179 &, 584 & ,360 & ,181 & ,085 &, 149 &,- 066 &,- 005 &, 110 \\
\hline & MET6 & ,198 & ,509 & ,299 & ,273 & , 180 & ,084 &,- 118 & ,037 & ,056 \\
\hline \multirow{6}{*}{$\begin{array}{c}\text { Persuasão } \\
\text { (PER) }\end{array}$} & PES5 & ,190 & ,104 & ,720 & ,194 & ,014 & ,023 & ,063 &,- 006 &,- 007 \\
\hline & PES2 & ,066 &, 173 & ,714 & ,077 & , 174 &,- 003 & ,079 & ,063 & ,086 \\
\hline & PES4 &, 120 &, 051 & ,706 & ,046 &,- 032 & ,096 & ,090 & , 140 & , 151 \\
\hline & PES6 & ,031 & ,161 & 690 & ,007 & ,245 & 097 & ,009 & ,265 & ,097 \\
\hline & PES3 & , 177 & ,119 & ,583 & ,223 & ,081 & ,048 & ,037 & ,284 & ,042 \\
\hline & PES1 & ,094 & , 140 & ,531 & ,011 & ,267 & ,048 & ,036 & ,072 & ,400 \\
\hline \multirow{5}{*}{$\begin{array}{c}\text { Controle } \\
\text { (CON) }\end{array}$} & CON3 & ,123 & , 139 & ,068 & ,748 & ,082 & , 147 & ,188 & ,190 & ,007 \\
\hline & CON4 & ,150 & , 184 & , 108 & ,711 & , 135 & ,061 & ,199 & ,065 & , 133 \\
\hline & CON2 & ,126 & , 178 & , 100 & ,700 & ,067 & ,135 &, 173 & ,067 & ,055 \\
\hline & CON1 & ,139 & , 165 & , 157 & ,609 & , 121 &, 144 & ,012 & , 165 & , 187 \\
\hline & CON5 & ,211 & , 162 & , 153 & ,536 & ,204 & ,080 & ,254 & ,100 & ,078 \\
\hline
\end{tabular}


ISSN: 2594-4827

\begin{tabular}{|c|c|c|c|c|c|c|c|c|c|c|}
\hline \multirow{4}{*}{$\begin{array}{l}\text { Rede de Relações } \\
\text { (RR) }\end{array}$} & RR2 & ,177 & ,007 & , 140 & ,061 & ,804 & ,099 & ,094 & ,054 &,- 012 \\
\hline & RR3 & ,161 & , 176 & , 108 & ,101 & ,790 & 099 & ,004 & , 125 & ,053 \\
\hline & RR4 & ,159 & ,106 & ,088 & 167 & 696 &, 121 & ,070 & ,216 & ,131 \\
\hline & RR1 & ,267 & ,082 & , 165 & , 182 & ,651 &, 112 & ,077 & ,040 & , 166 \\
\hline \multirow{4}{*}{$\begin{array}{c}\text { Intenção } \\
\text { Empreendedora } \\
\text { (IE) }\end{array}$} & IE1 & ,148 & ,193 & , 012 & ,075 & , 142 & 810 & ,016 &,- 038 & ,004 \\
\hline & IE3 & ,103 & ,081 & , 103 & , 125 & ,075 & ,806 & , 150 & ,050 & ,106 \\
\hline & IE2 & ,124 & ,108 & ,056 & 207 &, 170 & ,787 & ,007 & ,019 & ,086 \\
\hline & IE4 & ,048 &, 054 & ,070 & ,060 & ,019 & ,698 & ,153 & ,163 &, 185 \\
\hline \multirow{3}{*}{$\begin{array}{c}\text { Planejamento } \\
\text { (PLA) }\end{array}$} & PLA3 & ,084 & ,128 & ,067 & ,242 & ,051 & ,079 & ,770 &, 153 &,- 005 \\
\hline & PLA2 & 077 & ,077 & ,052 & ,104 & ,101 & ,081 & ,738 &,- 037 &, 180 \\
\hline & PLA1 & , 150 & 047 & , 107 & 269 & ,039 & , 150 & ,682 &, 143 & 040 \\
\hline \multirow{3}{*}{$\begin{array}{l}\text { Eficiência } \\
\text { (EFI) }\end{array}$} & EF1 & ,110 & ,139 & ,266 & , 120 & ,131 & ,091 & ,154 & ,728 & ,003 \\
\hline & EF2 & ,081 & ,105 & ,220 & ,234 & ,229 & ,077 & ,083 & ,699 &, 158 \\
\hline & EF3 & ,187 & ,082 & , 182 & ,214 & ,108 & ,030 & ,050 & ,592 & ,296 \\
\hline \multirow{3}{*}{$\begin{array}{l}\text { Oportunidade } \\
\text { (OP) }\end{array}$} & OP5 & ,151 & ,071 & ,229 & , 161 & ,096 & ,066 & ,057 &,- 007 & ,675 \\
\hline & OP2 & ,115 & , 182 & ,082 & , 152 & ,086 &, 111 & , 129 & ,108 & ,622 \\
\hline & OP1 & ,183 & ,116 & ,071 & ,007 &, 044 & ,223 & ,044 & ,239 & ,611 \\
\hline
\end{tabular}

Nota: Método de Extração: Análise dos Componentes Principais. Método de Rotação: Varimax com normatização de Kaiser.

Fonte: Dados da pesquisa (2017)

Com base na Tabela 2, observa-se que o componente 1 contempla os itens relacionados à dimensão persistência; o componente 2 agrupa os itens da dimensão metas; o componente 3 agrupa os itens relacionados à persuasão; o componente 4 está voltado para o controle; o componente 5 agrupa as redes de relações; o construto IE ficou agrupado no componente 6; planejamento, eficiência e oportunidade, ficaram respectivamente nos componentes 7, 8 e 9 . Destarte, verificou-se que as dimensões propostas por Santos (2008) para a escala de PE e IE foram confirmadas, com exceção da dimensão informações que foi excluída na pré-análise por não apresentar os parâmetros necessários, conforme descrito na seção de metodologia.

\section{Associação entre Perfil dos Estudantes e Intenção Empreendedora}

Conforme discutido anteriormente, para a operacionalização ANACOR, faz-se necessária a execução do teste qui-quadrado, que deve apresentar significância estatística ao nível de 5\% 
(FÁVERO et al., 2009). A Tabela 3 apresenta o teste qui-quadrado realizado entre o perfil dos estudantes e a variável referente ao construto IE.

Tabela 3 - Teste Qui-Quadrado para as Análises de Correspondência.

\begin{tabular}{lcc}
\hline \multicolumn{1}{c}{ Associações } & Significância & Associação Satisfatória \\
\hline Intenção Empreendedora x Curso & 0,000 & Sim \\
Intenção Empreendedora x Série & 0,048 & Sim \\
Intenção Empreendedora x Gênero & 0,587 & Não \\
Intenção Empreendedora x Idade & 0,028 & Sim \\
\hline
\end{tabular}

Fonte: Dados da pesquisa (2017).

Com base no que é apresentado na Tabela 3, observa-se que as variáveis série, curso e idade apresentaram significância estatística em níveis satisfatórios (inferior a 5\%), podendo assim inferir que há associação entre estas varáveis e a IE. No que tange à variável gênero, esta não apresentou associação, com níveis de significância estatística adequados. As associações entre a IE e o perfil dos estudantes são apresentadas nas figuras a seguir.

Figura 1 - Mapa perceptual da associação entre intenção empreendedora e curso.

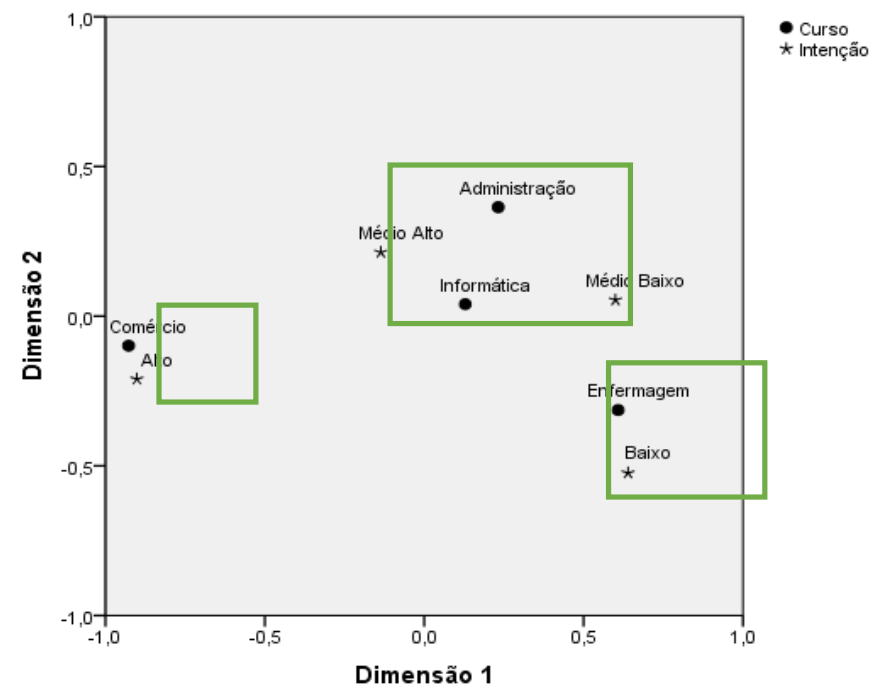

Fonte: Dados da pesquisa (2017).

Com base no que é apresentado na Figura 1, observa-se que há proximidade entre as variáveis no mapa perceptual, revelando que os alunos do curso técnico em comércio estão 
associados a um alto nível de IE. Os alunos dos cursos técnicos em administração e informática apresentaram associação com nível médio alto de IE. Já os estudantes do curso técnico em enfermagem apresentaram associação com baixa IE.

Figura 2 - Mapa perceptual da associação entre intenção empreendedora e série.

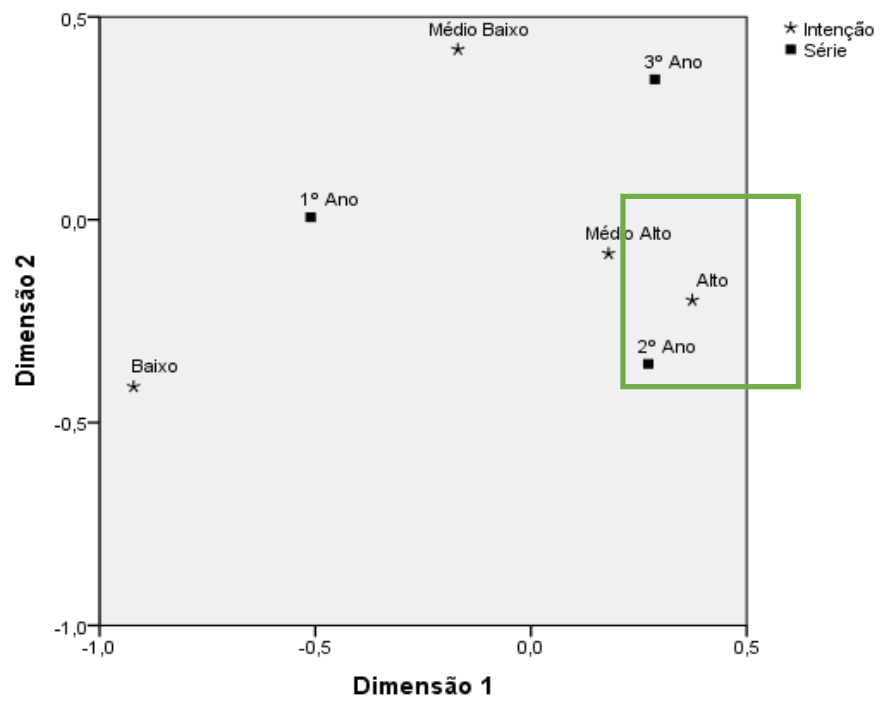

Fonte: Dados da pesquisa (2017).

Considerando as informações contidas na Figura 2, observa-se que os estudantes do $2^{\circ}$ ano estão associados a uma alta IE. O último mapa perceptual é apresentado na Figura 3 e evidencia a associação entre a IE e a idade dos estudantes.

Figura 3 - Mapa perceptual da associação entre IE e idade.

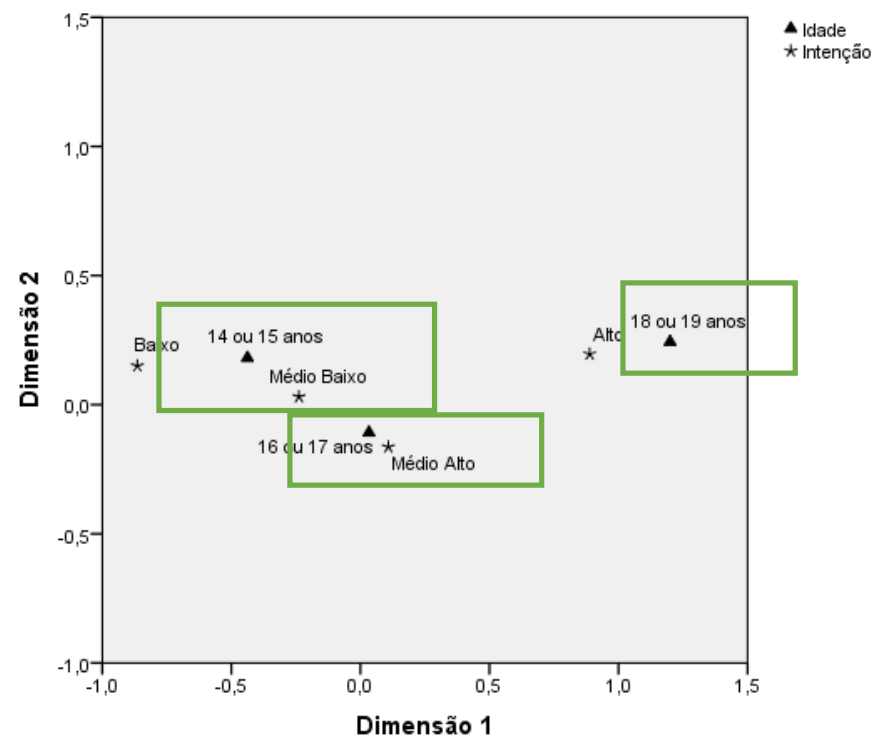


Fonte: Dados da pesquisa (2017).

Com base no mapa perceptual apresentado na Figura 3, observa-se uma alta IE daqueles estudantes com idade de 18 ou 19 anos. Os estudantes com idade de 16 ou 17 anos apresentaram IE média alta. Já os estudantes mais jovens, com idades entre 14 e 15 anos, apresentaram IE baixa. Esses resultados indicam que os alunos com maior idade tendem a apresentar maior IE.

\section{Influência do Potencial Empreendedor na Intenção Empreendedora dos Estudantes}

A fim de verificar a influência do PE sobre a IE dos estudantes, realizou-se uma regressão linear múltipla, em que alocou-se como a variável dependente a medida da IE, e como variáveis independentes as oito variáveis relacionadas ao PE: (i) persuasão; (ii) metas; (iii) persistência; (iv) controle; (v) rede de relações; (vi) planejamento; (vii) eficiência; e (viii) oportunidade.

A Tabela 4 apresenta os valores dos coeficientes das variáveis independentes do modelo, bem como os valores para o teste $t$, teste $\mathrm{F}, \mathrm{R}^{2}$ e a significâncias estatísticas. Observou-se que o teste $\mathrm{F}$ apresentou significância estatística ao nível de $1 \%$ (sig. = 0,000), indicando que pelo menos uma das variáveis independentes, ou seja, variáveis relacionadas ao PE, influencia a variável dependente, no caso, a IE dos estudantes. Além disso, o modelo de regressão não apresentou problemas de multicolinearidade entre as variáveis independentes, tendo em vista que o teste de Variance Inflation Factor (VIF) indicou que todas as variáveis apresentaram escores inferiores a 10, denotando nível aceitável de multicolinearidade (HAIR JR. et al., 2009).

Tabela 4 - Resultados da Regressão Linear Múltipla.

\begin{tabular}{|c|c|c|c|c|c|c|c|}
\hline \multicolumn{8}{|c|}{ Variável Dependente = Intenção Empreendedora (IE); N = 477} \\
\hline \multirow{2}{*}{$\begin{array}{l}\text { Variáveis } \\
\text { Independentes }\end{array}$} & \multirow{2}{*}{$\begin{array}{c}\text { Coeficiente } \\
\text { Padronizado } \\
\text { (Beta) }\end{array}$} & \multirow[b]{2}{*}{$t$} & \multirow[b]{2}{*}{ Sig. } & \multirow[b]{2}{*}{ VIF } & \multirow[b]{2}{*}{$\mathbf{R}^{2}$} & \multicolumn{2}{|c|}{ Teste $\mathbf{F}$} \\
\hline & & & & & & Valor & Sig. \\
\hline (Constant) & 0,273 & 0,957 & 0,339 & - & \multirow{6}{*}{0,249} & \multirow{6}{*}{19,424} & \multirow{6}{*}{0,000} \\
\hline Persuasão & 0,075 & 1,381 & 0,168 & 1,825 & & & \\
\hline Metas & $\mathbf{0 , 1 2 1} * *$ & 2,308 & 0,021 & 1,702 & & & \\
\hline Persistência & $-0,050$ & $-0,964$ & 0,336 & 1,679 & & & \\
\hline Controle & $0,129 * *$ & 2,286 & 0,023 & 1,977 & & & \\
\hline Rede de Relações & $0,132 * * *$ & 2,639 & 0,009 & 1,555 & & & \\
\hline
\end{tabular}


SSN: $2594-4827$

$\begin{array}{lllll}\text { Planejamento } & \mathbf{0 , 1 0 8} * * & 2,282 & 0,023 & 1,400 \\ \text { Eficiência } & -0,010 & -0,188 & 0,851 & 1,728 \\ \text { Oportunidade } & \mathbf{0 , 1 8 1} * * * & 3,717 & 0,000 & 1,464\end{array}$

Nota: (***) Significância ao nível de 1\%; (**) Significância ao nível de 5\%.

Fonte: Dados da pesquisa (2017).

Com base no que é apresentado na Tabela 4, verifica-se que o $\mathrm{R}^{2}$ é de $24,9 \%$, indicando o quanto a variável dependente é explicada pelas variáveis independentes. O valor do Beta indica a intensidade do efeito que cada variável independente tem sobre a variável dependente. Foram consideradas significantes as variáveis que apresentaram significância estatística inferior ao nível de 5\% (sig. < 0,05). O modelo revela que as variáveis metas, controle, rede de relações, planejamento e oportunidade exercem efeito positivo na IE.

\section{DISCUSSÃO DOS RESULTADOS}

Os achados desta pesquisa indicaram que, de modo geral, os estudantes dos cursos técnicos em comércio, administração e informática apresentaram IE superior aos estudantes do curso técnico em enfermagem. Nesse contexto, Iizuka e Moraes (2014) argumentam que os cursos na área de gestão devem estimular o empreendedorismo entre os estudantes, logo, o fato dos cursos de comércio e administração estarem associados a uma IE superior pode estar associado aos conteúdos estudados nesses cursos, o que fortalece e desenvolve a cultura empreendedora entre esses alunos.

Ainda, Guimarães e Azambuja (2010) advogam que as tecnologias da informação e da comunicação têm se tornado cada dia mais importantes nos processos de inovação e empreendedorismo, sugerindo que existe uma forte relação entre eles. A ideia de Guimarães e Azambuja (2010) alinha-se aos resultados desta pesquisa à medida em que se verificou que estudantes do curso técnico em informática apresentaram associação com uma IE média alta, denotando uma relação positiva entre o curso de informática e a IE.

No que se refere aos estudantes do curso de enfermagem, verificou-se que esses alunos apresentaram IE baixa. Roncon e Munhoz (2009) verificaram que, de fato, estudantes de enfermagem tendem a apresentar fraca ou nenhuma tendência empreendedora. Os autores discutem que a grande maioria dos estudantes de enfermagem pretende encaminhar sua profissão em atividades assistenciais, o que pode estar associado a esta baixa IE. 
No que concerne à associação entre IE e a série dos estudantes, constatou-se que os alunos do $2^{\circ}$ ano do ensino médio associam-se a uma alta IE. Não há uma explicação clara em relação a esta associação, porém, ao serem analisadas as matrizes curriculares dos cursos e os documentos disponibilizados pela Secretaria de Educação do Estado do Ceará (SEDUC-CE), observou-se que todos os cursos contam com um eixo de disciplinas diversificadas, focadas no desenvolvimento pessoal e social do aluno, entre elas, destaca-se a oferta da disciplina de empreendedorismo no $1^{\mathrm{o}}$ ano do ensino médio. Logo, uma possível explicação para a alta IE dos estudantes do $2^{\circ}$ ano do ensino médio poderia ser o fato desses alunos terem concluído a disciplina de empreendedorismo, o que proporciona a estes alunos uma maior percepção e compreensão sobre as questões envolvendo o empreendedorismo (SEDUC-CE, 2018).

Em relação à associação entre a idade dos estudantes e a IE, ficou evidenciado que os estudantes mais jovens (14 ou 15 anos) tendem a apresentar IE baixa ou média baixa, já os estudantes de 16 ou 17 anos apresentaram IE média alta e os estudantes mais velhos (18 ou 19 anos) apresentaram associação com alta IE. Esses resultados sugerem que existe uma associação positiva entre idade e IE. Diferentemente desta pesquisa, Ferreira, Alcântara e Freitas (2013) não encontraram diferença significativa no perfil empreendedor dos respondentes em relação às faixas etárias, indicando que, em linhas gerais, os respondentes de todas as idades apresentaram resultados semelhantes.

No que tange ao modelo de regressão, verificou-se que as variáveis metas, controle, rede de relações, planejamento e oportunidade influenciam positivamente a IE. Nessa seara, Minello, Bürger e Krüger (2017) asseveram que, para obter êxito, o empreendedor deve traçar metas de longo, médio e curto prazo, delineando estratégias para alcançar seus objetivos. Paço et al. (2011) discutem que a IE é um estado da mente que conduz o indivíduo a um determinado objetivo, sendo necessárias as definições de metas e meios para alcançá-lo.

Em relação à variável controle, Souza et al. (2016) argumentam que os controles estão relacionados à capacidade que o indivíduo tem de monitorar a implementação dos planos elaborados, manter registros e utilizá-los no processo de tomada de decisão. Nesse contexto, Leite, Moraes e Salazar (2014) argumentam que os controles são essenciais para a adaptação e sobrevivência de empreendimentos em contextos competitivos e de adaptação.

No tocante das redes de relações, Gimenez e Gimenez (2015) argumentam que as redes sociais e de relações são fundamentais para o desenvolvimento de novos empreendimentos, uma vez que é por meio delas que o indivíduo tem acesso a informações, conhecimento e 
recursos que podem ser úteis para a criação de negócios. Ainda sobre as redes de relações, Padilla-Meléndez, Fernández-Gámez e Molina-Gómez (2014) advogam que a gestão das relações tem importante papel no desenvolvimento da orientação empreendedora.

No que concerne à variável planejamento, compreende-se que ela está relacionada à capacidade do indivíduo para planejar suas atividades definindo objetivos, detalhando as tarefas e trabalhando com planos, execução e controle (SOUZA et al., 2016). Nessa perspectiva, Seidahmetov et al. (2014) identificaram, em sua pesquisa, que o planejamento é um dos fatores mais importantes para quem deseja iniciar um negócio.

Ainda, discute-se que a percepção sobre a oportunidade empreendedora é fundamental no campo do empreendedorismo e está associada ao descobrimento, assimilação e exploração de oportunidades de negócios (ALBUQUERQUE; TEIXEIRA, 2016). Gürol e Atsan (2006) asseveram que empreendedores estão sempre procurando por oportunidades, logo, a busca por oportunidades é uma característica intrínseca àqueles que apresentam IE. Em linhas gerais, compreende-se que os resultados desta pesquisa evidenciaram que indivíduos com PE para delinear metas, implementar controles, construir redes de relações, elaborar planejamentos e que identificam oportunidades tendem a apresentar maior IE.

\section{CONSIDERAÇÕES FINAIS}

Esta pesquisa objetivou analisar o PE e a IE de estudantes da educação profissional no Ceará. Para tanto, realizou-se uma pesquisa do tipo survey, com abordagem quantitativa, em que foram aplicados questionários com os estudantes de uma EEEP, no Estado do Ceará. A amostra foi composta por 477 estudantes de quatro diferentes cursos técnicos integrados ao ensino médio: (i) técnico em administração; (ii) técnico em comércio; (iii) técnico em enfermagem e; (iv) técnico em informática. Para a análise de dados, foram utilizadas técnicas de análise descritiva AFE, ANACOR e regressão linear múltipla.

Os resultados indicaram que os alunos do curso de comércio apresentaram alta IE, enquanto os alunos dos cursos de administração e informática apresentaram IE média alta e os alunos de enfermagem IE baixa. Além disso, verificou-se uma associação de alta IE com os alunos do $2^{\circ}$ ano do ensino médio. Ainda, observou-se uma associação positiva entre a idade e a IE. O modelo de regressão revelou que as seguintes variáveis do PE influenciam positivamente a IE: metas, controle, rede de relações, planejamento e oportunidade. 
Os resultados desta pesquisa contribuem para a área de empreendedorismo à medida em que verificou fatores que estão associados à IE de estudantes da educação profissional de nível médio, preenchendo uma lacuna na literatura no que concerne ao perfil empreendedor desses estudantes, uma vez que a maioria dos estudos dedicam-se a analisar o perfil empreendedor de estudantes de graduação. Além disso, a pesquisa agrega para a discussão sobre a educação empreendedora no âmbito da educação formal e dá destaque a uma política pública de educação que vem se evidenciando em todo o Brasil, como é o caso das EEEPs no Estado do Ceará, dando projeção e visibilidade a uma política de educação diferenciada e orientada ao empreendedorismo e à formação profissional para o trabalho.

O estudo tem como limitação o fato de ter sido realizado com alunos de uma única unidade de educação. Assim, os resultados aqui obtidos dizem respeito à realidade desta escola, logo, a realidade do perfil empreendedor dos alunos de outras EEEPs e outras instituições de ensino podem apresentar diferenças nos resultados, uma vez que cada instituição apresenta diferentes núcleos gestores e corpos docentes, além das diferenças regionais e culturais, o que pode influenciar na percepção dos estudantes sobre o PE e a IE.

Sugere-se, para pesquisas futuras, a inserção de outros testes estatísticos, como teste de hipóteses, modelagem de equações estruturais, análise de cluster, entre outros métodos que tragam diferentes evidências empíricas sobre o empreendedorismo. Ainda, encoraja-se a realização de pesquisas qualitativas a fim de sejam explorados os "porquês" que emergem em meio aos achados sobre o tema.

\section{REFERÊNCIAS}

ALBUQUERQUE, A. R. P.; TEIXEIRA, R. M. O processo de identificação e exploração de oportunidade empreendedora com base no modelo de aprendizagem organizacional $4 \mathrm{i}$.

Revista de Ciências da Administração, v. 18, n. 44, p. 25-37, 2016.

ALMEIDA, K.; SOUZA NETO, S. P.; NUNES, A. Q.; STTEFANELLO, M. A influência do ensino do empreendedorismo no potencial empreendedor do aluno. Revista de Negócios, v. 13, n. 2, p. 67-76, 2008.

ARAÚJO, R. M.; OLIVEIRA, F. P.; CHRISTO, R. S.; SILVA, D. O. Empreendedorismo: uma investigação na evolução da perspectiva empreendedora dos estudantes de uma IES privada no Rio Grande do Norte. Revista Eletrônica de Estratégia \& Negócios, v. 5, n. 1, p. 28-66, 2012. 
BIRCHLER, E. A.; TEIXEIRA, A. A intenção empreendedora de estudantes e os fatores que a influenciam. Revista de Negócios, v. 22, n. 2, p. 7-22, 2017.

CEARÁ. Lei No 14.273, de 19 de dezembro de 2008. Dispõe sobre a criação das Escolas Estaduais de Educação Profissional - EEEP, no âmbito da Secretaria da Educação, e dá outras providências. Assembleia Legislativa do Estado do Ceará. Disponível em: <http://www.al.ce.gov.br/legislativo/legislacao5/leis2008/14273.htm>. Acesso em: $10 \mathrm{jan}$. 2018.

CHING, H. Y.; KITAHARA, J. R. Propensão a empreender: uma investigação quantitativa baseada nas características empreendedoras de alunos do curso de administração. Revista de Ciências da Administração, v. 17, n. 43, p. 99-111, 2015.

DINIS, A.; PAÇO, A.; FERREIRA, J.; RAPOSO, M.; RODRIGUES, R. G. Psychological characteristics and entrepreneurial intentions among secondary students. Education + Training, v. 55, n. 8/9, p. 763-780, 2013.

DORNELAS, J. C. Empreendedorismo: transformando ideias em negócios. Rio de Janeiro: Campus, 2005.

ECKERT, A.; OLEA, P. M.; DORION, E. C. E.; MECCA, M. S.; ECKERT, M. G. O perfil empreendedor na graduação: um estudo comparativo entre ingressantes e concluintes. Revista Pensamento Contemporâneo em Administração, v. 7, n. 2, p. 61-76, 2013.

FÁVERO, L.P.; BELFIORE, P.; SILVA, F.L., CHAN, B.L. Análise de dados: modelagem multivariada para tomada de decisões. Rio de Janeiro: Campus, 2009.

FERREIRA, A. C.; ALCÂNTARA, V. C.; FREITAS, F. M. Adaptação, validação e discussões da aplicação de uma escala de medida do potencial empreendedor em universitários. Revista Pensamento Contemporâneo em Administração, v. 7, n. 3, p. 115$138,2013$.

GIMENEZ, F. A. P. GIMENEZ, S. C. Capital social e redes sociais empreendedoras na criação e crescimento de uma empresa de cicloturismo. Turismo em Análise, v. 26, n. 3, p. 616-638, 2015.

GUIMARÃES, S. M. K.; AZAMBUJA, L. R. Empreendedorismo high-tech no Brasil: condicionantes econômicos, políticos e culturais. Revista Sociedade e Estado, v. 25, n. 1, p. 93-121, 2010.

GUROL, Y.; ATSAN, N. Entrepreneurial characteristics amongst university students: some insights for entrepreneurship education and training in Turkey. Education + Training, v. 48, n. 1, p. 25-38, 2006.

HAIR JR., J.F.; WILLIAM, B.; BABIN, B.; ANDERSON, R.E. Análise multivariada de dados. 6 a ed. Porto Alegre: Bookman, 2009.

HISRICH, R. D.; PETERS, M. P. Empreendedorismo. 5a ed. Porto Alegre: Bookman, 2004. 
HONG, Z.; HONG, T.; CUI, Z.; LUZHUANG, W. Entrepreneurship quality of college students related to entrepreneurial education: empirical study on psychological and behavioral characteristics. Energy Procedia, v. 17, p. 1907-1913, 2012.

IIZUKA, E. S.; MORAES, G. H. S. M. Análise do potencial e perfil empreendedor do estudante de Administração e o ambiente universitário: reflexões para instituições de ensino. Administração: Ensino e Pesquisa, v. 15, n. 3, p. 593-593, 2014.

KOE, W. L.; SA'ARI, J. R.; MAJID, I. A.; ISMAIL, K. Determinants of entrepreneurial intention among millennial generation. Social and Behavioral Sciences, v. 40, p. 197-208, 2012.

LEITE, Y. V. P.; MORAES, W. F. A.; SALAZAR, V. S. Propensão à adaptação no empreendedorismo internacional: uma análise qualitativa de exportadoras do semiárido. Revista de Administração da UNIMEP, v. 12, n. 3, p. 207-227, 2014.

LIMA, E.; LOPES, R. M. A.; NASSIF, V. M. J.; SILVA, D. Ser seu próprio patrão? Aperfeiçoando-se a educação superior em empreendedorismo. Revista de Administração Contemporânea, v. 19, n. 4, p. 419-439, 2015.

LIMA, S. H. O.; CEGLIA, D.; REBOUÇAS, S. M. D. P.; TEIXEIRA, A. A. C. Modelagem de intenção empreendedora de estudantes universitários usando equações estruturais. Revista Pretexto, v. 17, n. 2, p. 2-65, 2016.

MALACARNE, R.; BRUNSTEIN, J.; BRITO, M. D. Formação de técnicos agropecuários empreendedores: o caso do IFES e sua participação na OBAP. Revista de

Empreendedorismo e Gestão de Pequenas Empresas, v. 3, n. 2, p. 20-41, 2014.

MCCLELLAND, D. A sociedade competitiva: realização e progresso social. Rio de Janeiro: Expressão e cultura, 1972.

MINELLO, I. F.; BÜRGER, R. E.; KRÜGER, C. Características comportamentais empreendedoras: um estudo com acadêmicos de administração de uma universidade brasileira. Revista de Administração da UFSM, v. 10, Edição Especial, p. 72-91, 2017.

NABI, G.; WALMSLEY, R. H. A. Entrepreneurial intentions among students: towards a refocused research agenda. Journal of Small Business and Enterprise Development, v. 17, n. 4, p. 537-551, 2010.

PAÇO, A.; FERREIRA, J.; RAPOSO, M.; RODRIGUES, R. G.; DINIS, A. Entrepreneurial intention among secondary students: findings from Portugal. International Journal of Entrepreneurship and Small Business, v. 13, n. 1, p. 92-106, 2011.

PADILLA-MELÉNDEZ, A.; FERNÁNDEZ-GÁMEZ, M. A.; MOLINA-GÓMEZ, J. Feeling the risks: effects of the development of emotional competences with outdoor training on the entrepreneurial intent of university students. International Entrepreneurial Management, v. 10, p. 861-884, 2014. 
PANC, I. Investigating the entrepreneurial potential of students: design and preliminary validity data of the assessment center method. Social and Behavioral Sciences, v. 203, p. 393-399, 2015.

ROCHA, E. L. C.; FREITAS, A. A. F. Avaliação do ensino de empreendedorismo entre estudantes universitários por meio do perfil empreendedor. Revista de Administração Contemporânea, v. 18, n. 4, p. 465-486, 2014.

RONCON, P. F.; MUNHOZ, S. Estudantes de enfermagem têm perfil empreendedor? Revista Brasileira de Enfermagem, v. 62, n. 5, p. 695-700, 2009.

ROSIQUE-BLASCO, M.; MADRID-GUIJARRO, A.; GARCÍA-PÉREZ-DE-LEMA, D. Entrepreneurial skills and socio-cultural factors: an empirical analysis in secondary education students. Education + Training, v. 58, n. 7/8, p.815-831, 2016.

SANTOS, P. C. F. Uma escala para identificar potencial empreendedor. 2008. 364 f. Tese (Doutorado em Engenharia de Produção) - Universidade Federal de Santa Catarina, Florianópolis, 2008.

SEDUC - Secretaria da Educação do Estado do Ceará. Educação Profissional. 2018. Disponível em: < http://www.educacaoprofissional.seduc.ce.gov.br/> Acesso em: $13 \mathrm{abr}$. 2018.

SEIDAHMETOVA, M.; IBRAIMOVAB, S.; YESBOLOVAC, A.; MERGENBAYEVAD, A.; ZHADIGEROVAE, G.; AHELOVAF, A. Development of entrepreneurial potential of students through system of professional education. Social and Behavioral Sciences, v. 143, p. 615-620, 2014.

SILVA, C. R. M.; OLIVEIRA, L. V. C.; PINHO, A. P. M. Perfil empreendedor de estudantes de um curso técnico em administração: um estudo sobre a percepção de professores e estudantes. Educação Online, n. 25, p. 141-165, 2017.

SILVEIRA, M. B.; SANCHES, C. Formação empreendedora: análise das características empreendedoras entre os estudantes do ensino técnico. Revista de Tecnologia Aplicada, v. 6, n. 3, p. 46-71, 2017.

SIQUEIRA, R. R.; COSTA, B. S.; SACRAMENTO, T. B. F. Percepções empreendedoras em tempos de crise: olhares dos discentes do curso subsequente em edificações - IFS campus Lagarto/SE. Educação Online, n. 24, p. 74-85, 2017.

SOUZA, G. H. S.; SANTOS, P. C. F.; LIMA, N. C.; CRUZ, N. J. T.; LEZANA, A. G. R. Entrepreneurial potential and success in business: a study on elements of convergence and explanation. Revista de Administração da Mackenzie, v. 17, n. 5, p. 188-215, 2016.

VARAMÄKI, E.; JOENSUU, S.; TORNIKOSKI, E.; VILJAMAA, A. The development of entrepreneurial potential among higher education students. Journal of Small Business and Enterprise Development, v. 22, n. 3, p. 563-589, 2015. 
YILDIRIM, N.; ASKUN, O.B. Entrepreneurship intentions of public universities in Turkey: going beyond education and research? Social and Behavioral Sciences, v. 58, p. 953-963, 2012. 